\title{
Blood concentrations and renal clearance of water-soluble vitamins in outpatients with ulcerative colitis
}

\author{
HIROMI IWAKAWA ${ }^{1}$, TOMIHO FUKUI ${ }^{2}$, TSUTOMU FUKUWATARI ${ }^{3}$, SHIGEKI BAMBA $^{4}$, \\ MASAYA SASAKI $^{4}$, TOMOYUKI TSUJIKAWA ${ }^{4}$, YUKIO DOI ${ }^{1}$ and KATSUMI SHIBATA ${ }^{3}$ \\ ${ }^{1}$ Department of Food Science and Human Nutrition, Faculty of Agriculture, Ryukoku University, \\ Otsu, Shiga 520-2194; ${ }^{2}$ Department of Nutrition, Faculty of Health and Nutrition, Shubun University, \\ Ichinomiya, Aichi 491-0938; ${ }^{3}$ Department of Nutrition, School of Human Cultures, The University of Shiga Prefecture, \\ Hikone, Shiga 522-8533; ${ }^{4}$ Department of Medicine, Shiga University of Medical Science, Otsu, Shiga 520-2192, Japan
}

Received January 4, 2018; Accepted January 21, 2019

DOI: $10.3892 /$ br.2019.1191

\begin{abstract}
Few studies have investigated the association between dietary intake and blood concentrations of water-soluble vitamins in patients with ulcerative colitis (UC). In the present study, vitamin concentrations were measured in the blood and urinary excretion of 23 outpatients with UC and compared against a control group of 20 healthy participants. A weighed food record procedure was used to ensure controlled macronutrient and vitamin intakes of the UC cohort. Individuals in the control group were given a semi-purified diet for 8 days prior to assessment. Multiple linear regression analysis was used to identify important differences in vitamin concentrations, independent of sex, age and other confounding variables. The blood concentrations of vitamins $\mathrm{B}_{2}, \mathrm{C}$, niacin and folate were markedly lower in the patients with UC than those in the control group, and the renal clearance of vitamins $\mathrm{B}_{1}, \mathrm{~B}_{6}, \mathrm{~B}_{12}$ and folate was notably higher in the UC cohort. It was concluded that vitamins $\mathrm{B}_{2}, \mathrm{C}$, niacin and folate were at significantly lower concentrations in patients with UC following adjustment for coexisting factors. The lower levels of niacin may be partially due to impaired reabsorption. Chronic inflammation, common in patients with UC, with may contribute to the lower levels of other vitamins by rendering amino acid and carbohydrate metabolism into a hypermetabolic state. As the role of vitamins in metabolic activity is constant and pervasive, nutritional management including the application of water-soluble vitamins appears important for patients suffering from UC.
\end{abstract}

Correspondence to: Mr. Hiromi Iwakawa, Department of Food Science and Human Nutrition, Faculty of Agriculture, Ryukoku University, 1-5 Yokotani, Seta Oe-cho, Otsu, Shiga 520-2194, Japan E-mail: iwakawa@agr.ryukoku.ac.jp

Key words: water-soluble vitamins, blood vitamin levels, urine vitamin excretions, ulcerative colitis, human, Japanese

\section{Introduction}

Ulcerative colitis (UC) is a chronic inflammatory disease of the large intestine, the characteristic symptoms of which are abdominal pain and cramping, blood in stools, diarrhea, vomiting and weight loss (1). As with other types of inflammatory bowel disease (IBD), including Crohn's disease, the etiology of UC remains to be fully elucidated, however, factors contributing to its development, including the environment, genetic predisposition, intestinal microflora and pathological immune responses, are well recognized (2-4). UC is most common in North America, England and North-Western Europe, although its incidence outside these regions has increased markedly since the 1980's $(5,6)$. This globalization appears to be associated with a Western diet and lifestyle, which emphasizes the importance of the effect of the environment on the occurrence of UC (4,7). IBD is managed with changes in lifestyle in addition to pharmacological and surgical treatments (8).

Vitamins, in their presence as much as their absence, are important in the pathophysiology of IBD. The most serious problem associated with vitamins in IBD is anemia due to deficiencies in iron, vitamin $B_{12}$ or folate. The causes of these deficiencies are different: Iron is depleted by chronic gastrointestinal blood loss; vitamin $\mathrm{B}_{12}$ is inhibited by malabsorption secondary to terminal ileitis; folate deficiency may occur as a result of sulfasalazine therapy (9). Elsewhere, it has been suggested that ascorbic acid (vitamin C), one of the most common antioxidants in biological systems, helps to fight inflammation and oxidative stress through the activation of intracellular molecular pathways $(10,11)$. By trapping radicals, ascorbic acid prevents the cell membrane oxidation and injury caused by reactive oxygen species (12). In addition, among the general health benefits provided by ascorbic acid supplementation, there are distinct advantages, including its roles in fighting metabolic disease or cancer (13). The role of vitamin D in the promotion of healthy bones is well established, however, this vitamin is also emerging as a multifunctional vitamin in IBD. It has been shown to be linked with various other functions, including anti-inflammatory and anticarcinogenic actions in the gastrointestinal tract (14). Among patients with 
IBD, vitamin D deficiency has been reported to be inversely associated with the disease activity of Crohn's disease but not with that of UC (15). Vitamin E has been reported to act as an anti-inflammatory and antioxidant in acetic acid-induced UC in rats (16).

Although there has been interest in the involvement of vitamins in the development and relapse of UC, there is limited data on the association between dietary intake and blood concentrations of water-soluble vitamins in patients with UC. With this in mind, the aim of the present study was to make a comprehensive comparison between the concentrations of water-soluble vitamins in the blood and urinary excretion of UC sufferers with a group of healthy control subjects.

\section{Materials and methods}

\section{Participants}

Patients with UC. A total of 23 patients (in remission, 8 men and 9 women; with active UC, 2 men and 4 women; mean age, 43.6 years; range: $20-74$ years) who visited the outpatient clinic of Shiga University of Medical Science Hospital (Shiga, Japan) were enrolled in the present study. All patients were treated with medicines for UC, including salazosulfapyridine (SASP) and 5-ASA. A number of patients were treated with prednisolone or an immunosuppressant, including azathioprine. The study was fully explained to each patient and they provided informed consent. Patients with UC reporting a history of major abdominal surgery, including colectomy, or of other gastrointestinal illness, carcinoma or other inflammatory and infectious disorders were excluded. This part of the study was performed between August and December 2010, in accordance with the Helsinki Declaration (October 2000). The protocol for was approved by the Institutional Review Board of the Shiga University of Medical Science. (no. 22-41, 2010).

Control participants. A total of 20 healthy, Japanese college students (10 men/10 women, mean age: 20.7 years, range 19-23 years), volunteered for the present study. The physical examination and blood tests performed prior to the experiment showed normal values. The study was reviewed and approved by the Ethical Committee of the Independent Administrative Agency, National Institute of Health and Nutrition (Tokyo, Japan). All participants were housed in the same facility for 8 days. A daily schedule imposed lights-out at 10:00 p.m. in order to promote sleep and wake-up at 06:00 a.m. The precise design of the experiment has been described elsewhere (17). This part of the study was performed between the March $1^{\text {st }}$ and March $8^{\text {th }}, 2002$ for the women, and between August $27^{\text {th }}$ and September $3^{\text {rd }}, 2002$ for the men.

\section{Blood and urine sample collection}

Patients with UC. Fasting blood samples were collected in EDTA tubes. Whole blood and plasma samples were stored at $-20^{\circ} \mathrm{C}$ for later analysis. In addition 24-h urine samples were collected on the day prior to the blood tests. The urine samples were maintained on ice until they had been measured and were immediately analyzed in order to avoid the destruction of water-soluble vitamins. The method of analysis is described below under. Following analysis, the samples were stored at $-20^{\circ} \mathrm{C}$.
Control participants. The collection of 24-h urine samples was performed from the second urination on day 7 to the first urination on day 8. Following measurement of the urine samples, they were immediately treated following the same protocol as the patients with UC in the preceding paragraph. Blood samples were collected from a cubital vein at 08:30 a.m., prior to breakfast on day 8 , were analyzed immediately to avoid the destruction of water-soluble vitamins and were then stored at $-20^{\circ} \mathrm{C}$.

\section{Dietary assessment}

Patients with UC. Food intake was recorded by each patient using a weighed food record procedure with supplemental use of photography at home. A registered dietician provided instructions on weighing and taking photographs. This regime was followed for 3 days prior to assessment. The validation of this method has been reported elsewhere (18). The daily intakes of macro- and micronutrients for each patient were calculated using software (Excel Eiyokun version 4.5, Kenpakusha, Inc. Tokyo, Japan) based on the $5^{\text {th }}$ revised and enlarged edition of the Standard Tables of Food Composition in Japan (19).

Controlparticipants. The mealtimes were as follows: Breakfast at 08:00-09:00 a.m., lunch at 12:30-13:10 p.m., and dinner at 18:30-19:00 p.m. The subjects consumed a semi-purified diet based on Japanese Dietary Reference Intakes (20) during the experiment. The composition and quantities of the semi-purified diet were as described previously (17).

Chemicals. Thiamin hydrochloride, riboflavin, pyridoxine hydrochloride, pyridoxal phosphate monohydrate, cyanocobalamin, nicotinamide, folate (pteroylmonoglutamic acid), and L (+)-ascorbic acid were purchased from Wako Pure Chemical Industries (Osaka, Japan). 4-Pyridoxic acid was made by ICN Pharmaceuticals (Costa Mesa, CA, USA) and obtained from Wako Pure Chemical Industries. N1-Methylnicotinamide (MNA) chloride was purchased from TokyoChemical Industries (Tokyo, Japan). $N^{1}$-Methyl-2-pyridone-5-carboxamide (2-Py) and $N^{1}$-methyl-4-pyridone-3-carboxamide (4-Py) were synthesized using the methods of Pullman and Colowick (21) and Shibata et al (22), respectively. All other chemicals used were of the highest purity available from commercial sources.

Analyses of blood and urine vitamins. The concentrations of total vitamin $B_{1}$ in the whole blood and urine samples were measured using the high performance liquid chromatography (HPLC)-post-labeled fluorescence method of Kimura et al (23) with modifications. The concentration of total vitamin $\mathrm{B}_{2}$ in the whole blood was determined using the HPLC-lumiflavin method of Ohkawa et al (24) with modifications. The urinary concentration of vitamin $\mathrm{B}_{2}$ was analyzed according to the method of Ohkawa et al (25). Pyridoxal phosphate (a coenzyme of vitamin $\mathrm{B}_{6}$ ) in the plasma was determined using the HPLC method (26). The concentration of 4-pyridoxic acid, a catabolite of vitamin $\mathrm{B}_{6}$, was measured in the urine using the HPLC method (27). Plasma and urine vitamin $B_{12}$ concentrations were assayed using a microbiological method with Lactobacillus delbruecki subsp. lactis (ATCC, Manassas, VA, USA; cat. no. 7870) (28). The total nicotinamide content in the whole blood samples was measured using the method of 
Table I. Background characteristics of participants.

\begin{tabular}{lcccr}
\hline Characteristics & $\begin{array}{c}\text { Control participants } \\
(\mathrm{n}=20)\end{array}$ & $\begin{array}{c}\text { Patients } \begin{array}{c}\text { with UC in remission } \\
(\mathrm{n}=17)\end{array} \\
\text { Age }(\text { years })\end{array}$ & $\begin{array}{c}\text { Patients with active UC } \\
(\mathrm{n}=6)\end{array}$ & P-value \\
Women $(\%)$ & $20.7 \pm 0.9$ & $41.8 \pm 14.9^{\mathrm{b}}$ & $44.7 \pm 15.7^{\mathrm{b}}$ & $<0.001$ \\
BMI $\left(\mathrm{kg} / \mathrm{m}^{2}\right)$ & 50 & 53 & 66 & 0.581 \\
Hb $(\mathrm{g} / \mathrm{dl})$ & $21.4 \pm 1.7$ & $21.9 \pm 3.6$ & $22.4 \pm 4.2^{\mathrm{a}}$ & 0.020 \\
Ht $(\%)$ & $14.1 \pm 1.5$ & $11.2 \pm 3.7$ & 0.124 \\
WBC $\left(\mathrm{x} 10^{3} / \mathrm{mm}^{3}\right)$ & & $41.5 \pm 3.7$ & $39.5 \pm 5.0$ & 0.285 \\
Alb $(\mathrm{g} / \mathrm{dl})$ & $5.8 \pm 1.8$ & $7.8 \pm 3.0$ & 0.046 \\
TP $(\mathrm{g} / \mathrm{dl})$ & $4.2 \pm 0.4$ & $3.8 \pm 0.7$ & 0.077 \\
T-Chol $(\mathrm{mg} / \mathrm{dl})$ & & $7.0 \pm 0.5$ & $7.1 \pm 0.6$ & 0.841 \\
CRP $(\mathrm{mg} / \mathrm{dl})$ & & $195 \pm 25$ & $188 \pm 49$ & 0.639 \\
CRE $(\mathrm{mg} / \mathrm{dl})$ & & $0.1 \pm 0.2$ & $1.8 \pm 4.2$ & 0.063 \\
eGFR (ml/min) & & $0.8 \pm 0.2$ & $0.9 \pm 0.4$ & 0.300 \\
& & $78.1 \pm 15.4$ & $73.6 \pm 22.4$ & 0.578 \\
\hline
\end{tabular}

Values are presented as the mean \pm standard deviation or $\%$ (for women). The $\chi^{2}$ test was used to compare dichotomous variables (\% women) among controls, patients with UC in remission phase, and patients with UC in active phase. Student's t-test was used to ascertain whether the means of two groups were statistically different from each other. Analysis of variance was used to compare the means of the three cohorts, followed a post-hoc Tukey HSD test when the F-value was significant at $\mathrm{P}<0.05$. ${ }^{\mathrm{a}} \mathrm{P}<0.05$ and ${ }^{\mathrm{b}} \mathrm{P}<0.01$ compared with the control by Tukey's post hoc analysis. UC, ulcerative colitis; BMI, body mass index; Hb, hemoglobin; Ht, hematocrit; WBC, white blood cell count; Alb, albumin; TP, total protein; T-chol, total cholesterol; CRP, C-reactive protein; CRE, creatinine; eGFR, estimated glomerular filtration rate.

Shibata et al (29). The quantities of Nam, 2-Py and 4-Py in the urine were measured simultaneously using the HPLC method of Shibata et al (22). The content of MNA was measured using the method of Shibata (30). The concentrations of plasma and urinary folate were determined via the microbioassay method using Lactobacillus casei (ATCC, cat. no. 2733) (31). The plasma and urine contents of reduced and oxidized ascorbic acid and 2,3-diketogluconic acid were determined using the HPLC method (32). The clearance rates of vitamins in $\mathrm{ml} / \mathrm{min}$ were calculated from the 24-h urinary excretion of vitamins and blood concentrations of vitamins.

Estimated glomerular filtration rate (eGFR). The body surface area (BSA) was calculated using the following formula: $\mathrm{BSA}=0.007184 \mathrm{x}$ body weight $(\mathrm{kg})^{0.425} \mathrm{x}$ height $(\mathrm{cm})^{0.725}(33)$. The eGFR in patients with UC was calculated using the following equation: eGFR $(\mathrm{ml} / \mathrm{min})=194 \times(B S A / 1.73) \times$ creatinine $(\mathrm{mg} / \mathrm{dl})^{-1.094} \mathrm{x} \mathrm{age}^{-0.287}$ for men, and $=194 \mathrm{x}(\mathrm{BSA} / 1.73) \mathrm{x}$ creatinine $(\mathrm{mg} / \mathrm{dl})^{-1.094} \mathrm{x}$ age $\mathrm{a}^{-0.287} \mathrm{x} 0.739$ for women (34). As serum creatinine concentrations from the control participants were not available, eGFR was estimated as $100 \mathrm{ml} / \mathrm{min}$.

Statistical analysis. SPSS Statistics version 23.0 (IBM Corp., Armonk, NY, USA) was used. The $\chi^{2}$ test was used to compare dichotomous variables among controls, patients with active UC, and patients with UC in remission. Student's t-test was used to confirm whether the means of two groups were statistically different from each other. One-way analysis of variance was used to compare the means of three groups, followed by post hoc application of the Tukey test when the F-value was significantly different at $\mathrm{P}<0.05$. With the exception of vitamin $B_{2}$, almost none of the means of variables in the patients with UC were statistically different when active and remission cases were compared. Coefficients for multiple linear regression models were used to examine the differences in blood vitamin concentrations between the UC cohorts and control groups $(35,36)$. As the distribution of blood vitamin $B_{12}$ concentration was positively skewed, a logarithmic transformation was used to normalize the distribution. Model 0 $=$ crude difference in patients and controls (patient - control). P-values were ascertained by linear regression analyses. Model 1 = age-adjusted difference. Model $2=$ Model 1 variables plus sex $($ male $=1$, female $=0)$, body mass index $\left(\mathrm{BMI} ; \mathrm{kg} / \mathrm{m}^{2}\right)$, eGFR, urinary excretion, and dietary intake of each vitamin. The above analyses were performed for blood vitamin $\mathrm{B}_{2}$ concentration in three groups (i.e., control, patients with active UC and those in remission) using dummy variables.

\section{Results}

Descriptive statistics. The basic characteristics of members of the UC and control groups are tabulated in Table I. BMI did not vary substantially even though the patients with UC had a higher mean age than the subjects in the control group. Men and women were equally represented in all groups. The mean albumin, C-reactive protein, creatinine, eGFR, hematocrit, hemoglobin, white blood cell, total cholesterol and total protein levels of the patients with UC are also shown in Table I. When the test results for patients in remission were compared against the patients with active UC, only the mean WBC of patients with active UC was notably higher. As expected, the CRP level of the patients with active UC was higher than that in patients in the remission phase. However, this difference was not statistically significant $(\mathrm{P}>0.05)$.

The macronutrient and vitamin intakes for all participants are listed in Table II. The recommended dietary 
Table II. Macronutrient and vitamin intakes of patients with UC and control participants.

\begin{tabular}{|c|c|c|c|c|c|}
\hline Variables & $\begin{array}{c}\text { Control } \\
\text { participants }\end{array}$ & $\begin{array}{l}\text { Patients with UC } \\
\text { in remission }\end{array}$ & $\begin{array}{l}\text { Patients with UC } \\
\text { in active phase }\end{array}$ & P-value & Vitamin RDA \\
\hline Total energy (kcal/day) & $2,050 \pm 256$ & $2,119 \pm 473$ & $1,968 \pm 578$ & 0.768 & - \\
\hline Protein (\% kcal/day) & $12.3 \pm 0.1$ & $15.0 \pm 2.1^{\mathrm{a}}$ & $15.2 \pm 1.7^{\mathrm{a}}$ & $<0.001$ & - \\
\hline Fat (\% kcal/day) & $19.8 \pm 0.2$ & $26.2 \pm 6.0^{\mathrm{a}}$ & $21.3 \pm 7.0$ & 0.001 & - \\
\hline Carbohydrate (\% kcal/day) & $66.1 \pm 1.2$ & $56.5 \pm 7.9^{\mathrm{a}}$ & $61.3 \pm 6.0$ & $<0.001$ & - \\
\hline Vitamin $B_{1}(\mathrm{mg} / 1,000 \mathrm{kcal} /$ day $)$ & $0.54 \pm 0.02$ & $0.51 \pm 0.11$ & $0.42 \pm 0.08^{\mathrm{a}}$ & 0.011 & 0.54 \\
\hline Vitamin $B_{2}(\mathrm{mg} / 1,000 \mathrm{kcal} /$ day $)$ & $0.85 \pm 0.01$ & $0.65 \pm 0.10^{\mathrm{a}}$ & $0.53 \pm 0.19^{\mathrm{a}, \mathrm{b}}$ & $<0.001$ & 0.60 \\
\hline Vitamin $\mathrm{B}_{6}(\mathrm{mg} / \mathrm{g}$ protein/day) & $0.031 \pm 0.003$ & $0.022 \pm 0.043^{\mathrm{a}}$ & $0.019 \pm 0.035^{\mathrm{a}}$ & $<0.001$ & 0.023 \\
\hline Vitamin $\mathrm{B}_{12}(\mu \mathrm{g} / 1,000 \mathrm{kcal} /$ day $)$ & $2.4 \pm 0.6$ & $4.1 \pm 1.6$ & $6.7 \pm 6.2^{\mathrm{a}}$ & 0.002 & 1.2 \\
\hline Vitamin C (mg/1,000 kcal/day) & $49.5 \pm 6.2$ & $67.5 \pm 34.5$ & $43.2 \pm 27.6$ & 0.061 & 48.8 \\
\hline Niacin $(\mathrm{mgNE} / 1,000 \mathrm{kcal} /$ day $)$ & $5.6 \pm 0.1$ & $10.5 \pm 3.4^{\mathrm{a}}$ & $10.7 \pm 3.5^{\mathrm{a}}$ & $<0.001$ & 5.8 \\
\hline Folate $(\mu \mathrm{g} / 1,000 \mathrm{kcal} /$ day $)$ & $99.0 \pm 12.4$ & $268.8 \pm 169.4^{\mathrm{a}}$ & $172.1 \pm 61.2$ & $<0.001$ & 117 \\
\hline $\mathrm{NaCl}$ (g/day) & $3.1 \pm 1.0$ & $9.3 \pm 2.2^{\mathrm{a}}$ & $10.2 \pm 1.2^{\mathrm{a}}$ & $<0.001$ & - \\
\hline
\end{tabular}

Values are presented as the mean \pm standard deviation, P-values and vitamin RDA. Vitamin RDA values for Japanese adults were obtained from (35). Analysis of variance was used to compare the means of the three cohorts, followed by a post-hoc Tukey HSD test when the F-value was significant at $\mathrm{P}<0.05$. For niacin intake, $1 \mathrm{mg} \mathrm{NE}=1 \mathrm{mg}$ niacin or $60 \mathrm{mg}$ tryptophan. ${ }^{\mathrm{P}}<0.01$ compared with the control by Tukey's post-hoc analysis; ${ }^{\mathrm{b}} \mathrm{P}<0.05$ between participants with UC in remission and patients with active UC, compared by Tukey's post-hoc analysis UC, ulcerative colitis; RDA, recommended dietary allowance; NE, niacin equivalent.

allowance (RDA) for vitamins, fixed by the Japanese Ministry of Health in 2010, are listed in the final column of Table II (37). Although the semi-purified diet consumed by control participants, who were assessed in 2002, was based on the RDA for 1999 (20), the RDA values for vitamins in 2010 are similar. For the macronutrients, the intakes of protein and fat were notably higher in the UC cohort than in the control group. The means for vitamins $\mathrm{B}_{1}, \mathrm{~B}_{2}$ and $\mathrm{B}_{6}$ did not vary markedly from the RDA values, however, the patients with UC in particular tended to have lower values. Almost half of the patients with UC had intakes of these vitamins that were below the RDA values. The means for $\mathrm{B}_{12}$, niacin and folate were generally higher than the RDA values. Compared with the controls, higher means were recorded in the active $\mathrm{UC}$ cohort for vitamin $\mathrm{B}_{12}$, in the remission UC cohort for folate, and in the two UC cohorts for niacin and $\mathrm{NaCl}$. Lower means were recorded in the patients with active $\mathrm{UC}$ for vitamin $\mathrm{B}_{1}$, and in the two UC cohorts for vitamin $\mathrm{B}_{2}$ and $\mathrm{B}_{6}$. Between the remission $\mathrm{UC}$ and the active $\mathrm{UC}$ cohorts, the mean value for vitamin $\mathrm{B}_{2}$ was lower in the active phase. The total energy and vitamin $\mathrm{C}$ intakes did not differ among the three groups.

Urinary vitamin excretion in patients with UC and controls. The urinary vitamin excretion values of the patients with UC and controls are listed in Table III. The mean urinary excretion of vitamin $\mathrm{B}_{12}$ was significantly lower in the patients with UC than in the control group, whereas the values for vitamin $B_{1}$ were notably higher. There were no differences in the remaining values between the UC and control groups.

Blood vitamin concentrations in patients with UC and controls. The blood vitamin concentrations of the patients with UC and the controls are listed in Table IV. Without adjustment (Model 0), the patients with UC exhibited higher concentrations than the control group for vitamins $\mathrm{B}_{1}$ and $\mathrm{B}_{12}$, and lower concentrations for the remaining vitamins. With adjustment for age (Model 1), the differences for all vitamins remained significant. With further adjustments for age, sex, BMI, eGFR, urinary excretions of vitamin and dietary intake of each vitamin (Model 2), the blood concentrations of vitamin $B_{2}$, vitamin $C$, niacin and folate remained significantly lower in the patients with UC than those in the controls. The results of the analyses for blood vitamin $B_{2}$ levels in the three groups (i.e., control, and patients with UC in remission and in the active phase) with use of dummy variables did not differ from the results of the two-group analyses.

Vitamin clearance in patients with UC and controls. The vitamin clearance rates of the UC and the control groups are listed in Table V. Compared with the control group, the mean clearance rates of vitamin $\mathrm{B}_{1}$ were significantly higher in the patients with active $\mathrm{UC}$ and those in remission compared with that in the control. The patients with $\mathrm{UC}$ in remission also had higher clearance rates of vitamin $\mathrm{B}_{6}, \mathrm{~B}_{12}$ and folate, whereas patients with UC in the active phase exhibited lower clearance rates of vitamin $B_{12}$. No significant differences were observed for the other values among the three groups.

\section{Discussion}

The principal finding of the present study investigating the association between dietary intake and blood concentrations of water-soluble vitamins in patients with UC was that concentrations of vitamin $B_{2}$, vitamin $C$, niacin and folate were markedly lower in patients with UC than in healthy control subjects, independent of age, BMI, dietary intake, eGFR and 
Table III. Urinary vitamin excretion in patients with UC and controls.

\begin{tabular}{lcccr}
\hline Variables & $\begin{array}{c}\text { Control } \\
\text { participants }\end{array}$ & $\begin{array}{c}\text { Patients with UC } \\
\text { in remission }\end{array}$ & $\begin{array}{c}\text { Patients with UC } \\
\text { in active phase }\end{array}$ & P-value \\
\hline Vitamin B $_{1}(\mathrm{nmol} /$ day) & $483.5 \pm 176.0$ & $3,209 \pm 1,065^{\mathrm{d}}$ & $2,994 \pm 2,430^{\mathrm{c}}$ & 0.002 \\
Vitamin $_{2}(\mathrm{nmol} / \mathrm{day})$ & $571 \pm 257$ & $606 \pm 112$ & $154 \pm 178$ & 0.474 \\
4-PIC $(\mathrm{mmol} / \mathrm{day})$ & $3.0 \pm 0.6$ & $4.2 \pm 3.0$ & 3.2 & 0.175 \\
Vitamin $_{12}$ (pmol/day) & $119.0 \pm 47.8$ & $42.9 \pm 19.2^{\mathrm{d}}$ & $27.3 \pm 14.1^{\mathrm{d}}$ & $<0.001$ \\
Vitamin C $\left(\mu\right.$ mol/day) $_{\text {Sum of niacin catabolites }}^{\mathrm{b}}$ & $144.1 \pm 49.6$ & $204.2 \pm 300.7$ & $87.2 \pm 72.8$ & 0.443 \\
$(\mu$ mol/day) & $28.7 \pm 9.4$ & $31.5 \pm 21.6$ & $31.0 \pm 15.5$ & 0.872 \\
Folate (nmol/day) & $21.1 \pm 3.1$ & $21.2 \pm 30.8$ & $19.7 \pm 17.7$ & 0.988 \\
\hline
\end{tabular}

Urinary vitamin excretion concentrations are presented as the mean \pm standard deviation. Analysis of variance was used to compare the means of the three cohorts, followed by a post hoc application of the Tukey test when the F-value was significant at $\mathrm{P}<0.05$. $\mathrm{B}_{1}$ to $\mathrm{C}$ denotes vitamin $\mathrm{B}_{1}$ to vitamin $\mathrm{C}$. ${ }^{\mathrm{a}} \mathrm{Catabolite}$ of vitamin $\mathrm{B}_{6}$. ${ }^{\mathrm{b}} \mathrm{Sum}$ of $N^{1}$-methylnicotinamide, $N^{1}$-methyl-2-pyridone-5-carboxamide and $N^{1}$-methyl-4-pyridone-3-carboxamide (major catabolites of niacin). ${ }^{\mathrm{c}} \mathrm{P}<0.05,{ }^{\mathrm{d}} \mathrm{P}<0.01$ compared with the control by Tukey's post-hoc analysis . UC, ulcerative colitis.

other confounding factors; and that for renal clearance, only niacin was notably higher in patients with UC.

Individuals suffering from UC are usually advised to follow a diet rich in energy and protein, but restricted in fat which can stimulate the mucous membrane of the large intestine and cause diarrhea (38). Patients are also advised to eat food with sufficient micronutrients to avoid inflammatory reactions. However, in the subjects who volunteered for the present study, those in the UC group actually had higher fat content in their diets than the controls. As the total protein and albumin levels remained within the normal range, no patients were classified as malnourished. Jowett et al suggested that a high-meat diet rich in sulfur and sulfate may be implicated in relapse of UC. Amino acids containing sulfur are abundant in animal proteins but not in soy protein, which may be recommended as a source of protein for patients with UC (39). For patients with IBD, it is recommended that vitamin intakes are above dietary reference intakes. In the present study, in which almost $50 \%$ of the UC patient group had vitamin $\mathrm{B}_{1}, \mathrm{~B}_{2}, \mathrm{~B}_{6}$ and $\mathrm{C}$ intakes below the RDA values, nutritional improvement with the possible inclusion of food supplements is recommended.

Vitamin deficiencies, if they occur in IBD, may not be attributed to a single cause (40). Inadequate intake of vitamins may be present in severe cases as patients may restrict their diet in order to reduce symptoms. The increased utilization of vitamins in the inflammatory process itself may contribute to the vitamin deficiencies of patients. The malabsorption caused by the presence of chronic diarrhea or intestinal dysfunctions may be additional factors. In this context, it is possible that chronic inflammation of the large intestine in patients with UC affects their gut flora, which is known to produce certain vitamins, including vitamin $\mathrm{B}_{2}$, niacin and folate. However, the vitamins, if synthesized, may not be absorbed as the large intestine lacks vitamin transporters. The supply of vitamins from the gut flora, if any, can be neglected in healthy individuals and patients with UC. In addition, in the case of water-soluble vitamins, their urinary excretion also requires consideration.
Vitamin $\mathrm{B}_{2}$ (riboflavin) is an architectural component of flavin mononucleotide and flavin adenine dinucleotide, which serve as prosthetic groups in flavoproteins. For example, a flavoprotein, succinate dehydrogenase catalyzing the oxidation reaction of succinic acid to fumaric acid is a key enzyme in tricarboxylic acid cycle for energy production (41). As patients with UC are in a hypercatabolic state due to inflammation and fever, their requirement for riboflavin may increase in catabolic metabolism, leading to lower level of vitamin $B_{2}$ in the blood. However, inflammation and fever are not the sole reasons for decreased levels of vitamin $\mathrm{B}_{2}$, as the blood level of vitamin $B_{1}$, which is also important in carbohydrate catabolism for energy production, was not lower in patients with UC than in the control group. Further investigation is required for clarifying the suitable levels of B group vitamins for patients with UC.

As vitamin $B_{12}$ is important for the normal formation of red blood cells, its serum level was examined in relation to anemia among patients with IBD in Brazil (42). The study by Antunes et al (42) reported that only 5\% of patients with UC exhibited vitamin $B_{12}$ deficiency, however, no data was reported for the serum level. In the present study, the vitamin $B_{12}$ level in patients with UC was significantly higher than that of in control individuals following adjustment for age (Model 1), however, the significance disappeared with further adjustment for sex, BMI, eGFR, urinary excretion of the vitamin and dietary intake of the vitamin (Model 2) as described above.

In the present study, the blood concentration of vitamin $\mathrm{C}$ was markedly lower in the patients with UC than in the control subjects. Fernandez-Banares et al also reported low vitamin C concentrations in patients with IBD (43). Vitamin C is absorbed throughout the whole of the small intestine. Unlike Crohn's disease, in which lesions develop in the small intestine, inflammation in UC is mainly confined to the colon $(2,8)$. Therefore, the absorption of vitamin $\mathrm{C}$ is not expected to be impaired in UC. The low concentration of vitamin $\mathrm{C}$ in the patients with UC may be due to the increased requirements for antioxidants triggered by colonic inflammation. It is well 
Table IV. Blood vitamin concentrations in patients with UC and controls.

\begin{tabular}{|c|c|c|c|c|c|}
\hline Variables & Mean \pm SD & Range & Difference & $\mathrm{P}$-value & $\mathrm{R}^{2}$-value \\
\hline \multicolumn{6}{|c|}{ Vitamin $\mathrm{B}_{1}(\mathrm{pmol} / \mathrm{ml})$} \\
\hline $\mathrm{UC}$ & $87.2 \pm 21.7$ & $42.6-136.6$ & & & \\
\hline Control & $86.1 \pm 18.7$ & $33.8-109.1$ & & & \\
\hline Model 0 & & & 1.06 & $<0.001$ & 0.001 \\
\hline Model 1 & & & 6.55 & $<0.001$ & 0.016 \\
\hline Model 2 & & & 23.9 & 0.210 & 0.214 \\
\hline \multicolumn{6}{|c|}{ Vitamin $\mathrm{B}_{2}(\mathrm{pmol} / \mathrm{ml})$} \\
\hline UC & $141.1 \pm 24.7$ & $86.1-186.5$ & & & \\
\hline Control & $214.7 \pm 22.8$ & $175-258$ & & & \\
\hline Model 0 & & & -73.5 & $<0.001$ & 0.713 \\
\hline Model 1 & & & -77.7 & $<0.001$ & 0.715 \\
\hline Model 2 & & & -86.3 & 0.025 & 0.830 \\
\hline \multicolumn{6}{|c|}{$\begin{array}{l}\text { Pyridoxal phosphate } \\
\text { (vitamin } \mathrm{B}_{6} \text { coenzyme; } \mathrm{pmol} / \mathrm{ml} \text { ) }\end{array}$} \\
\hline $\mathrm{UC}$ & $63.0 \pm 65.0$ & $14.0-344.1$ & & & \\
\hline Control & $78.7 \pm 15.2$ & $52.7-113.3$ & & & \\
\hline Model 0 & & & -15.7 & $<0.001$ & 0.026 \\
\hline Model 1 & & & 6.0 & $<0.001$ & 0.066 \\
\hline Model 2 & & & 9.8 & 0.59 & 0.242 \\
\hline \multicolumn{6}{|c|}{ Vitamin $B_{12}(\mathrm{pmol} / \mathrm{ml})^{\mathrm{a}}$} \\
\hline $\mathrm{UC}$ & $1.12(0.94,1.60)$ & $0.74-4.65$ & & & \\
\hline Control & $0.42(0.34,0.70)$ & $0.26-0.92$ & & & \\
\hline \multicolumn{6}{|l|}{$\log B_{12}$} \\
\hline $\mathrm{UC}$ & $0.09 \pm 0.19$ & $-0.13-0.67$ & & & \\
\hline Control & $-0.33 \pm 0.18$ & $-0.59-(-0.04)$ & & & \\
\hline Model 0 & & & 0.43 & $<0.001$ & 0.586 \\
\hline Model 1 & & & 0.38 & $<0.001$ & 0.590 \\
\hline Model 2 & & & 0.20 & 0.244 & 0.829 \\
\hline \multicolumn{6}{|c|}{ Vitamin C (nmol/ml) } \\
\hline $\mathrm{UC}$ & $39.9 \pm 18.1$ & $12.3-103.7$ & & & \\
\hline Control & $64.5 \pm 12.5$ & $47-100$ & & & \\
\hline Model 0 & & & -24.5 & $<0.001$ & 0.387 \\
\hline Model 1 & & & -25.3 & $<0.001$ & 0.388 \\
\hline Model 2 & & & -42.2 & 0.002 & 0.554 \\
\hline \multicolumn{6}{|c|}{ Niacin $(\mathrm{nmol} / \mathrm{ml})$} \\
\hline $\mathrm{UC}$ & $48.5 \pm 27.0$ & $23.4-120.4$ & & & \\
\hline Control & $60.5 \pm 5.6$ & $52.8-75.4$ & & & \\
\hline Model 0 & & & -12.0 & $<0.001$ & 0.086 \\
\hline Model 1 & & & -19.1 & $<0.001$ & 0.111 \\
\hline Model 2 & & & -42.8 & 0.003 & 0.270 \\
\hline \multicolumn{6}{|c|}{ Folate (pmol/ml) } \\
\hline $\mathrm{UC}$ & $9.8 \pm 7.3$ & $1.2-34.7$ & & & \\
\hline Control & $23.5 \pm 9.6$ & $10.7-51.6$ & & & \\
\hline Model 0 & & & -14.0 & $<0.001$ & 0.425 \\
\hline Model 1 & & & -17.8 & $<0.001$ & 0.453 \\
\hline Model 2 & & & -27.1 & 0.015 & 0.629 \\
\hline
\end{tabular}

Coefficients for multiple linear regression models were used to examine differences in blood vitamin concentrations between the UC and control groups. As the distribution of blood vitamin $\mathrm{B}_{12}$ concentration was positively skewed, a logarithmic transformation was used to normalize the distribution. Model 0: Crude difference in patients and controls (patient-control). P-values by linear regression analyses. Model 1: Age-adjusted difference. Model 2: Model 1 variables + sex, body mass index, estimated glomerular filtration rate, urinary excretion, and dietary intake of each vitamin. $\mathrm{R}^{2}$ is a goodness-of-fit measure. ${ }^{\text {a Vitamin }} \mathrm{B}_{12}$ concentrations are shown as median $\left(25^{\text {th }}, 75^{\text {th }}\right.$ percentile $)$. UC, ulcerative colitis; SD, standard deviation. 
Table V. Vitamin clearance rates $(\mathrm{ml} / \mathrm{min})$ in the $\mathrm{UC}$ and control groups.

\begin{tabular}{lccrr}
\hline Variable & $\begin{array}{c}\text { Control } \\
\text { participants }\end{array}$ & $\begin{array}{c}\text { Patients with UC } \\
\text { in remission }\end{array}$ & $\begin{array}{c}\text { Patients with UC } \\
\text { in active phase }\end{array}$ & P-value \\
\hline Vitamin $B_{1}$ & $4.04 \pm 1.55$ & $23.7 \pm 23.67^{\mathrm{a}}$ & $32.4 \pm 30.88^{\mathrm{b}}$ & 0.003 \\
Vitamin $\mathrm{B}_{2}$ & $1.87 \pm 0.86$ & $2.55 \pm 4.38$ & $0.734 \pm 0.713$ & 0.431 \\
Vitamin $\mathrm{B}_{6}$ & $27.5 \pm 7.0$ & $60.77 \pm 47.58^{\mathrm{a}}$ & $52.19 \pm 29.3$ & 0.010 \\
Vitamin $\mathrm{B}_{12}$ & $0.179 \pm 0.065$ & $0.263 \pm 0.123^{\mathrm{b}}$ & $0.152 \pm 0.11^{\mathrm{b}}$ & $<0.001$ \\
Niacin & $0.33 \pm 0.11$ & $0.45 \pm 0.31$ & $0.60 \pm 0.40$ & 0.080 \\
Folate & $0.70 \pm 0.23$ & $1.90 \pm 2.09^{\mathrm{a}}$ & $1.45 \pm 0.90$ & 0.032 \\
Vitamin $\mathrm{C}$ & $1.60 \pm 0.59$ & $3.11 \pm 4.10$ & $1.90 \pm 1.87$ & 0.243 \\
\hline
\end{tabular}

Vitamin clearance rates $(\mathrm{ml} / \mathrm{min})$ are presented as the mean \pm standard deviation. Analysis of variance was used to compare the means of the three groups, followed by a followed by a post-hoc Tukey HSD test when the F-value was significant at $\mathrm{P}<0.05$. ${ }^{\mathrm{a}} \mathrm{P}<0.05$ and ${ }^{\mathrm{b}} \mathrm{P}<0.01 \mathrm{compared}$ with the control by Tukey's post-hoc analysis. UC, UC, ulcerative colitis.

known that vitamin $\mathrm{C}$ acts as a potent antioxidant in the living body (44).

Despite a sufficient dietary intake of niacin, its concentration was lower in the UC group than in the control group. By contrast, niacin renal clearance was markedly higher in the UC group than in the control group. The lower concentration of niacin was likely due to a high urinary clearance of niacin. In addition, the increased catabolic metabolism in UC may contribute to the lower level of niacin. Niacin is an architectural component of pyridine nucleotide coenzymes, including nicotinamide adenine dinucleotide and nicotinamide adenine dinucleotide phosphate. The reduced forms of the pyridine nucleotide coenzymes also have anti-inflammatory activity (45).

The lower concentrations of folate in patients with UC in the present study may be associated with medications taken by the patients. Interactions with SASP and 5-ASA, therapeutic agents for UC, are known to cause vitamin deficiency, particularly for folate. Hoshino et al reported the case of a patient with UC who had developed folate-deficient megaloblastic anemia induced by SASP, with the symptom being aggravated further by the use of 5-ASA (46). SASP interferes with a folate recognition site that is common to three enzymes involved in folate metabolism, dihydrofolate reductase, methylenetetrahydrofolate reductase and serine transhydroxymethylase, and to the intestinal transport system (47). Although the jejunum appears to be clinically uninvolved in UC, changes in the structure and function of the small bowel have been described $(48,49)$. The malabsorption of folate due to the administration of SASP for UC may also be due to the inhibition of pteroylpoly- $\gamma$-carboxypeptidase (known as folate conjugate), which hydrolyzes poly-glutamate forms of tetrahydrofolates in foods to a mono-glutamate form of tetrahydrofolate in the intestinal jejunum prior to absorption (50).

The key strengths of the present study were as follows: i) the comprehensive measurement of blood, urine, and dietary intakes of water-soluble vitamins of subjects; and ii) the standardized collection of samples that were immediately analyzed with high-quality laboratory measurements. The cross-sectional design of the study was identified as a weakness, and results require interpretation with caution when considering cause-effect relationships. As the age ranges differed widely between the patients suffering from UC and healthy subjects, statistical analyses may have been affected. However, as $\mathrm{R}^{2}$, the goodness-of-fit measure for all of the blood vitamin concentrations augmented considerably from Model 0 to Model 2, the appropriateness of the statistical method appears to have be confirmed. Data on urinary creatinine of $\mathrm{NaCl}$ was not collected from the patients with UC, nor was blood creatinine in the control subjects. The eGFR was used for the UC cohort and a rate of $100 \mathrm{ml} / \mathrm{min}$ was used for the control subjects. The total number of subjects, including patients $(n=23)$ and controls $(n=20)$, may be considered small. However, by remaining vigilant regarding the behavior of $\mathrm{R}^{2}$ in the analyses, and by checking $\mathrm{R}^{2}$ behavior against comparable studies in the field, the number of subjects is considered to be adequate.

In conclusion, the blood concentrations of vitamin $\mathrm{B}_{2}$, vitamin $\mathrm{C}$, niacin and folate were significantly lower in patients with UC than in healthy subjects, independent of age and other confounding factors. Reductions in the blood concentrations of these vitamins in patients with UC may be of clinical significance, including in the forecasting, diagnosing and treatment of anemia in patients suffering from UC. Therefore, modifying the management of patients with UC, including adjustments in diet and/or vitamin supplementation, may be warranted when similar laboratory results are present.

\section{Acknowledgements}

Not applicable.

\section{Funding}

This study was supported by The University of Shiga Prefecture Grant for Special Research (grant no. 78).

\section{Availability of data and materials}

The datasets used in the present study are available from the corresponding author on reasonable request.

\section{Authors' contributions}

HI, ToF and KS conceived and designed the experiments; HI, TsF and KS analyzed the data; HI and YD wrote the first 
draft of the manuscript; TsF, KS and MS contributed to the writing of the manuscript; HI, ToF, TsF, SB, MS, TT, YD, and $\mathrm{KS}$ agreed with manuscript results and conclusions. All the authors reviewed and approved the final manuscript.

\section{Ethics approval and consent to participate}

All procedures performed in the study involving human participants were in accordance with the 1964 Helsinki Declaration and its later amendments or comparable ethical standards. The protocol for this study was approved by the Institutional Review Board of the Shiga University of Medical Science (no. 22-41, 2010). Written informed consent was obtained from the individual participants included in the study.

\section{Patient consent for publication}

Not applicable.

\section{Competing interests}

The authors declare that they have no competing interests.

\section{References}

1. Lochs H, Dejong C, Hammarqvist F, Hebuterne X, Leon-Sanz M, Schütz T, van Gemert W, van Gossum A, Valentini L, Lübke H, et al; DGEM (German Society for Nutritional Medicine); ESPEN (European Society for Parenteral and Enteral Nutrition): ESPEN Guidelines on Enteral Nutrition: Gastroenterology. Clin Nutr 25: 260-274, 2006.

2. Sartor RB: Mechanisms of disease: Pathogenesis of Crohn's disease and ulcerative colitis. Nat Clin Pract Gastroentero Hepatol 3: 390-407, 2006.

3. Danese $\mathrm{S}$ and Fiocchi C: Etiopathogenesis of inflammatory bowel diseases. World J Gastroenterol 12: 4807-4812, 2006.

4. Leone V, Chang EB and Devkota S: Diet, microbes, and host genetics: The perfect storm in inflammatory bowel diseases. J Gastroenterol 48: 315-321, 2013.

5. Matsuoka K and Watanabe M: Ulcerative colitis -recent advance in clinical practice and basic research. Nihon Shokakibyo Gakkai Zasshi 113: 407-412, 2016 (In Japanese).

6. Molodecky NA, Soon IS, Rabi DM, Ghali WA, Ferris M, Chernoff G, Benchimol EI, Panaccione R, Ghosh S Barkema HW and Kaplan GG: Increasing incidence and prevalence of the inflammatory bowel diseases with time, based on systematic review. Gastroenterology 142: 46-54 e42; quiz e30, 2012 .

7. Sincić BM, Vucelić B, Persić M, Brncić N, Erzen DJ, Radaković B, Mićović V and Stimac D: Incidence of inflammatory bowel disease in Primorsko-goranska County, Croatia, 2000-2004: A prospective population-based study. Scand J Gastroenterol 41: 437-444, 2006

8. Baumgart DC and Sandborn WJ: Inflammatory bowel disease: Clinical aspects and established and evolving therapies. Lancet 369: 1641-1657, 2007.

9. Nemeş RM, Pop CS, Calagiu D, Dobrin D, Chetroiu D, Jantea P and Postolache P: Anemia in Inflammatory Bowel Disease More Than an Extraintestinal Complication. Rev Med Chir Soc Med Nat Iasi 120: 34-39, 2016.

10. Sorice A, Guerriero E, Capone F, Colonna G, Castello G and Costantini S: Ascorbic acid: Its role in immune system and chronic inflammation diseases. Mini Rev Med Chem 14: 444-452, 2014.

11. Bernardo D, Martínez-Abad B, Vallejo-Diez S, Montalvillo E, Benito V, Anta B, Fernández-Salazar L, Blanco-Quirós A, Garrote JA and Arranz E: Ascorbate-dependent decrease of the mucosal immune inflammatory response to gliadin in coeliac disease patients. Allergol Immunopathol (Madr) 40: 3-8, 2012.

12. Romieu I: Nutrition and lung health. Int J Tuberc Lung Dis 9 : 362-374, 2005
13. Hosokawa Y, Monzen S, Yoshino H, Terashima S, Nakano M, Toshima K, Saga R and Kashiwakura I: Effects of X ray irradiation in combination with ascorbic acid on tumor control. Mol Med Rep 12: 5449-5454, 2015.

14. Narula N and Marshall JK: Management of inflammatory bowel disease with vitamin D: Beyond bone health. J Crohn's Colitis 6: 397-404, 2012.

15. Frigstad SO, Høivik M, Jahnsen J, Dahl SR, Cvancarova M, Grimstad T, Berset IP, Huppertz-Hauss G, Hovde Ø, Torp R, et al: Vitamin D deficiency in inflammatory bowel disease: Prevalence and predictors in a Norwegian outpatient population. Scand J Gastroenterol 52: 100-106, 2017.

16. Tahan G, Aytac E, Aytekin H, Gunduz F, Dogusoy G, Aydin S, Tahan V and Uzun H: Vitamin E has a dual effect of anti-inflammatory and antioxidant activities in acetic acid-induced ulcerative colitis in rats. Can J Surg 54: 333-338, 2011.

17. Shibata K, Fukuwatari T, Ohta M, Okamoto H, Watanabe T, Fukui T, Nishimuta M, Totani M, Kimura M, Ohishi N, et al: Values of water-soluble vitamins in blood and urine of Japanese young men and women consuming a semi-purified diet based on the Japanese Dietary Reference Intakes. J Nutr Sci Vitaminol (Tokyo) 51: 319-328, 2005.

18. Wang DH, Kogashiwa M, Ohta S and Kira S: Validity and reliability of a dietary assessment method: The application of a digital camera with a mobile phone card attachment. J Nutr Sci Vitaminol (Tokyo) 48: 498-504, 2002

19. Standard Tables Of Food Composition in Japan -2015- (Seventh Revised Edition). Documentation and Table. http://www.mext.go.jp/en/policy/science_technology/policy/title01/detail01/sdetail01/sdetail01/1385122.htm.

20. Ministry of Health: Labor and Welfare: Recommended Dietary Allowances in the Japanese Population. In: Dietary Reference Intakes. 6th edition. Ministry of Health, Labor and Welfare, pp112-114, Tokyo, 1999.

21. Pullman ME and Colowick SP: Preparation of 2- and 6-pyridones of N1-methylnicotinamide. J Biol Chem 206: 121-127, 1954

22. Shibata K, Kawada $T$ and Iwai K: Simultaneous micro-determination of nicotinamide and its major metabolites, N1-methyl-2-pyridone-5-carboxamide and N1-methyl-4-pyridone-3-carboxamide, by high-performance liquid chromatography. J Chromatogr A 424: 23-28, 1988.

23. Kimura M, Fujita T and Itokawa Y: Liquid-chromatographic determination of the total thiamin content of blood. Clin Chem 28: 29-31, 1982.

24. Ohkawa $\mathrm{H}$, Ohishi $\mathrm{N}$ and Yagi $\mathrm{K}$ : A simple method for micro-determination of flavin in human serum and whole blood by high-performance liquid chromatography. Biochem Int 4: 187-194, 1982.

25. Ohkawa H, Ohishi N and Yagi K: New metabolites of riboflavin appear in human urine. J Biol Chem 258: 5623-5628, 1983.

26. Rybak ME and Pfeiffer CM: Clinical analysis of vitamin $\mathrm{B}(6)$ : Determination of pyridoxal 5'-phosphate and 4-pyridoxic acid in human serum by reversed-phase high-performance liquid chromatography with chlorite postcolumn derivatization. Anal Biochem 333: 336-344, 2004.

27. Gregory JF III and Kirk JR: Determination of urinary 4-pyridoxic acid using high performance liquid chromatography. Am J Clin Nutr 32: 879-883, 1979.

28. Watanabe F, Abe K, Fujita T, Goto M, Hiemori M and Nakano Y: Effects of Microwave Heating on the Loss of Vitamin B(12) in Foods. J Agric Food Chem 46: 206-210, 1998.

29. Shibata K, Kawada T and Iwai K: High-performance liquid chromatographic determination of nicotinamide in rat tissue samples and blood after extraction with diethyl ether. J Chromatogr A 422: 257-262, 1987.

30. Shibata K: Ultramicro-determination of N1-methylnicotinamide in urine by high performance liquid chromatography. Vitamins 61: 599-604, 1987.

31. Aiso K and Tamura T: Trienzyme treatment for food folate analysis: Optimal $\mathrm{pH}$ and incubation time for alpha-amylase and protease treatment. J Nutr Sci Vitaminol (Tokyo) 44: 361-370, 1998.

32. Kishida E, Nishimoto Y and Kojo S: Specific determination of ascorbic acid with chemical derivatization and high-performance liquid chromatography. Anal Chem 64: 1505-1507, 1992.

33. DuBois D and Dubois E: A formula to estimate the approximate surface area if height and weight be known. Arch Intern Med (Chic) 17: 863-871, 1916.

34. Matsuo S, Imai E, Horio M, Yasuda Y, Tomita K, Nitta K, Yamagata K, Tomino $\mathrm{Y}$, Yokoyama $\mathrm{H}$ and Hishida A; Collaborators developing the Japanese equation for estimated GFR: Revised equations for estimated GFR from serum creatinine in Japan. Am J Kidney Dis 53: 982-992, 2009. 
35. Zhao L, Stamler J, Yan LL, Zhou B, Wu Y, Liu K, Daviglus ML, Dennis BH, Elliott P, Ueshima H, et al; INTERMAP Research Group: Blood pressure differences between northern and southern Chinese: role of dietary factors: the International Study on Macronutrients and Blood Pressure. Hypertension 43: $1332-1337,2004$.

36. Nakamura $Y$, Ueshima H, Okuda N, Higashiyama $A$, Kita Y, Kadowaki T, Okamura T, Murakami Y, Okayama A, Choudhury SR, et al; INTERLIPID Research Group: Relation of dietary and other lifestyle traits to difference in serum adiponectin concentration of Japanese in Japan and Hawaii: The INTERLIPID Study. Am J Clin Nutr 88: 424-430, 2008.

37. Ministry of Health: Labor and Welfare: Recommended Dietary Allowances in the Japanese Population. In: Dietary Reference Intakes. Ministry of Health, Labor and Welfare, pp147-188, Tokyo, 2010.

38. Japanese Society for Parenteral and Enteral Nutrition (JSPEN): Guidelines for the use of parenteral and enteral nutrition. 3rd edition. JSPEN, pp295-298, Tokyo, 2013.

39. Jowett SL, Seal CJ, Pearce MS, Phillips E, Gregory W, Barton JR and Welfare MR: Influence of dietary factors on the clinical course of ulcerative colitis: A prospective cohort study. Gut 53: 1479-1484, 2004.

40. Chiarello PG, Penaforte FR, Japur CC, Souza CD, Vannucchi H and Troncon LE: Increased folate intake with no changes in serum homocysteine and decreased levels of C-reactive protein in patients with inflammatory bowel diseases. Dig Dis Sci 54: $627-633,2009$

41. Renkema GH, Wortmann SB, Smeets RJ, Venselaar H, Antoine M, Visser G, Ben-Omran T, van den Heuvel LP, Timmers HJ, Smeitink JA, et al: SDHA mutations causing a multisystem mitochondrial disease: Novel mutations and genetic overlap with hereditary tumors. Eur J Hum Genet 23: 202-209, 2015.
42. Antunes CV, Hallack Neto AE, Nascimento CR, Chebli LA, Moutinho IL, Pinheiro Bdo V, Reboredo MM, Malaguti C, Castro AC and Chebli JM: Anemia in inflammatory bowel disease outpatients: prevalence, risk factors, and etiology. Biomed Res Int 2015: 728925, 2015.

43. Fernandez-Banares F, Abad-Lacruz A, Xiol X, Gine JJ, Dolz C, Cabre E, Esteve M, Gonzalez-Huix F and Gassull MA: Vitamin status in patients with inflammatory bowel disease. Am J Gastroenterol 84: 744-748, 1989

44. Kojo S: Vitamin C: Basic metabolism and its function as an index of oxidative stress. Curr Med Chem 11: 1041-1064, 2004.

45. Chai JT, Digby JE and Choudhury RP: GPR109A and vascular inflammation. Curr Atheroscler Rep 15: 325, 2013.

46. Hoshino J, Sugawara K, Ishikawa S, Hayami Y, Sakurazawa T, Tanaka T, Yamamoto N, Hashimoto M, Yamamoto T and Hoshihara Y: A case of ulcerative colitis with folate deficient megaloblastic anemia induced by sulfasalazine. Nihon Shokakibyo Gakkai Zasshi 96: 840-845, 1999 (In Japanese).

47. Selhub J, Dhar GJ and Rosenberg IH: Inhibition of folate enzymes by sulfasalazine. J Clin Invest 61: 221-224, 1978.

48. Arvanitakis C: Abnormalities of jejunal mucosal enzymes in ulcerative colitis and Crohn's disease. Digestion 19: 259-266, 1979.

49. Binder HJ and Ptak T: Jejunal absorption of water and electrolytes in inflammatory bowel disease. J Lab Clin Med 76: 915-924, 1970

50. Halsted CH, Gandhi G and Tamura T: Sulfasalazine inhibits the absorption of folates in ulcerative colitis. N Engl J Med 305: 1513-1517, 1981. 